This document is confidential and is proprietary to the American Chemical Society and its authors. Do not copy or disclose without written permission. If you have received this item in error, notify the sender and delete all copies.

\title{
Cometabolic enzymatic transformation of organic micropollutants under methanogenic conditions
}

\begin{tabular}{|r|l|}
\hline Journal: & Environmental Science \& Technology \\
\hline Manuscript ID & Draft \\
\hline Danuscript Type: & Article \\
\hline Complete List of Authors: & $\begin{array}{l}\text { Gonzalez-Gil, Lorena; Universidade de Santiago de Compostela, } \\
\text { Department of Chemical Engineering } \\
\text { Carballa, Marta; University of Santiago de Compostela, Department of } \\
\text { Chemical Engineering } \\
\text { Lema, Juan; University of Santiago de Compostela, Department of } \\
\text { Chemical Engineering }\end{array}$ \\
\hline
\end{tabular}

SCHOLARONE

Manuscripts 


\section{Cometabolic enzymatic transformation of organic}

\section{2 micropollutants under methanogenic conditions}

3 Lorena Gonzalez-Gil*, Marta Carballa, Juan M. Lema

4

5 Department of Chemical Engineering, Institute of Technology, Universidade de Santiago de

6 Compostela, 15782 Santiago de Compostela, Spain

$9 \quad{ }^{*}$ Corresponding author.

12 Keywords: acetate kinase, anaerobic digestion, biotransformation, cometabolism, organic

13 micropollutants, sewage sludge.

14 


\section{ABSTRACT}

16 Anaerobic digestion (AD) has been shown to have the biological potential to decrease the 17 concentrations of several organic micropollutants (OMPs) from sewage sludge. However, the 18 mechanisms and factors behind these biotransformations, which are essential for elucidating the 19 possible transformation products and to foster the complete removal of OMPs via operational 20 strategies, remain unclear. Therefore, this study investigated the transformation mechanisms of 2120 OMPs during the methanogenic step of $\mathrm{AD}$ with a focus on the role of acetate kinase (AK),

22 which is a key enzyme in methane production. The results from lab-scale methanogenic reactors 23 showed that this step accounts for much of the reported OMPs biotransformation in AD. 24 Furthermore, enzymatic assays confirmed that AK transforms galaxolide, naproxen, 25 nonylphenol, octylphenol, ibuprofen, diclofenac, bisphenol $\mathrm{A}$ and triclosan. Except for 26 galaxolide, for which further studies are required to refine conclusions, the OMP's chemical 27 structure was a determinant for the AK action because only compounds that contain a carboxyl 28 or a hydroxyl group and that have a moderate steric hindrance were enzymatically transformed, 29 likely by phosphorylation. For these 7 compounds, this enzymatic mechanism accounts for 10$3090 \%$ of the measured methanogenic biotransformation, suggesting that other active enzymes of 31 the AD process are also involved in OMPs biotransformation.

\section{Abstract Art}

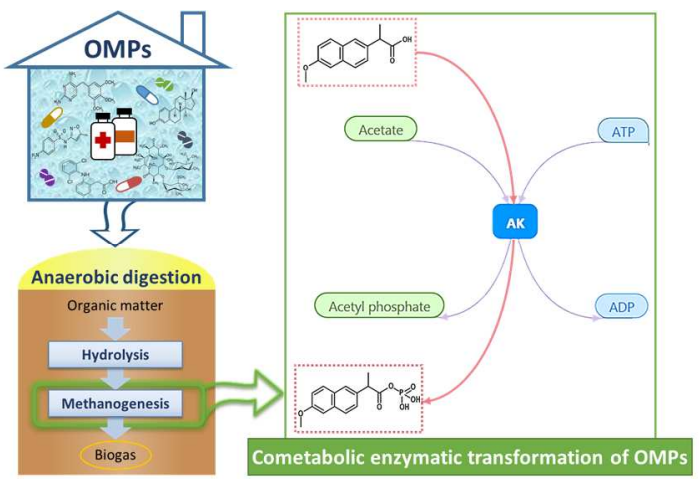




\section{INTRODUCTION}

34 The increasing use of pharmaceuticals, personal care products, hormones and many other 35 organic compounds in our daily life has resulted in the release of these organic micropollutants 36 (OMPs) into the environment via diverse pathways. ${ }^{1}$ There is evidence of negative effects of

37 OMPs on human and ecosystem health, ${ }^{2}$ which suggests that reduction measures should be 38 applied, especially for one of the main sources of OMP discharge: effluents of sewage treatment 39 plants (STPs).

40 Anaerobic digestion (AD) is widely used in STPs for sludge stabilization prior to its 41 application in agricultural soils as a biosolid. Significant quantities of OMPs arrive at the sludge

42 treatment line sorbed onto solids ${ }^{3}$ but also solubilized in the water phase of the sludge, achieving 43 concentrations up to $90-140 \mu \mathrm{g} \mathrm{L}^{-1}$ for musk fragrances (galaxolide and tonalide), $40 \mu \mathrm{g} \mathrm{L}^{-1}$ for 44 triclosan, $25 \mu \mathrm{g} \mathrm{L}{ }^{-1}$ for ibuprofen, and $1-10 \mu \mathrm{g} \mathrm{L}^{-1}$ for hormones (estrone and 17 $\beta$-estradiol). ${ }^{4}$ 45 Most of these OMPs remain in the digested sludge, ${ }^{4}$ thus its use as a fertilizer might transfer 46 OMPs to the soil. ${ }^{5}$

47 Despite the environmental risks associated with biosolid-amended soils, ${ }^{5}$ few studies have 48 investigated the fate of OMPs during AD. ${ }^{4,6-12}$ They conclude that $\mathrm{AD}$ is able to biologically 49 transform OMPs, but the degree of removal of some compounds is still controversial, and few 50 transformation products (TPs) have been identified, which indicates the poor understanding of 51 the microbial mechanisms and factors behind these biotransformations. ${ }^{3}$ Therefore, to develop 52 strategies that promote the complete elimination of OMPs and to predict the environmental risks 53 of the TPs that are generated, it is essential to understand the biotransformation pathways 54 involved in AD. 
55 To date, only rare and inconclusive information is available about the relationship between 56 anaerobic populations and the removal of OMPs. ${ }^{13}$ This lack of knowledge is justified by the 57 complexity of the biological and chemical processes involved in the four steps of AD (Figure 1): 58 hydrolysis, acidogenesis, acetogenesis and methanogenesis. ${ }^{14}$ According to the taxonomic 59 analysis of Guo et al., ${ }^{15}$ Bacteria ( $\left.\sim 93 \%\right)$ was more abundant than Archaea (methanogens) $(\sim 6 \%)$ 60 on sewage sludge AD. Among bacteria, Proteobacteria (41\%), Firmicutes (13\%) and 61 Bacteroidetes (10\%) are the most abundant populations, while Methanosaeta (26\%), 62 Methanospirillum (13\%), Methanosarcina (13\%), Methanoculleus (11\%) and Methanoregula $63(8 \%)$ are the dominant methanogenic genera. During the four AD steps, these microorganisms 64 produce a broad diversity of enzymes to degrade the organic substrates. Depending on their 65 specificity, these enzymes can also modify the structures of OMPs despite being non-growth 66 substrates. This biochemical process is known as cometabolism, and it is considered by many 67 authors to be a major removal mechanism of OMPs during the biological treatment of 68 wastewater. ${ }^{16-21}$ The action of enzymes on OMPs is poorly investigated, and most studies have 69 focused on oxygenases. ${ }^{21-23}$ A recent study by Krah et al. ${ }^{24}$ tested the activity of a cocktail of 70 extracted enzymes from activated sludge towards OMPs. By measuring several TPs and using 71 several enzymatic inhibitors, they concluded that amide hydrolases could be involved in the 72 biotransformation of acetaminophen, acetyl sulfamethoxazole, atenolol and bezafibrate, that 73 oxidoreductases transform 10-OH-carbamazepine and that erythromycin is affected by 74 hydrolases acting on ester bonds. However, the suspected participation of particular enzymes in 75 the cometabolic biotransformation of OMPs was not definitively confirmed because the 76 identification of enzymes by indirect measurements is unreliable, and the isolation of target 77 enzymes has not yet been reported. ${ }^{21}$ Although no studies about the enzymatic transformation 78 routes of OMPs during $\mathrm{AD}$ have been found, it could be hypothesized that hydrolases from the 
79 two first AD steps, which perform relatively simple reactions, are involved in the

80 biotransformation of some OMPs, as was demonstrated for activated sludge systems. ${ }^{24}$ For the

81 more specific acetogenic and methanogenic steps, the removal of polycyclic aromatic

82 hydrocarbons (PAH) has been linked to methanogenesis, ${ }^{25}$ but the type of enzymatic

83 biotransformation that could occur is not clear.

84 The aceticlastic methanogenesis (Figure 1) is performed by the archaea Methanosaeta and

85 Methanosarcina and it is considered the main pathway in the synthesis of methane in anaerobic

86 digesters. ${ }^{15,26}$ The first step in the methanization of acetate by Methanosarcina species is the

87 phosphorylation of acetate to acetyl phosphate (Figure 1 and Figure S1), which is performed by

88 the key intracellular enzyme acetate kinase (AK). Then, the acetyl phosphate is further converted

89 to acetyl-CoA by phosphotransacetylase $(\mathrm{PTA})^{27}$ and the aceticlastic methanization continues

90 with the action of other enzymes (Figure S1). In addition, AK associated with PTA catalyzes the

91 reverse reaction (conversion of acetyl-CoA to acetate; Figure 1) in fermentative prokaryote

92 bacteria during acetogenesis. ${ }^{28} \mathrm{AK}$ is a relatively specific enzyme but, in addition to acetate, it is

93 able to phosphorylate other substrates to a lower extent; ${ }^{29,30}$ thus, AK might also have effects on

94 some OMPs. 


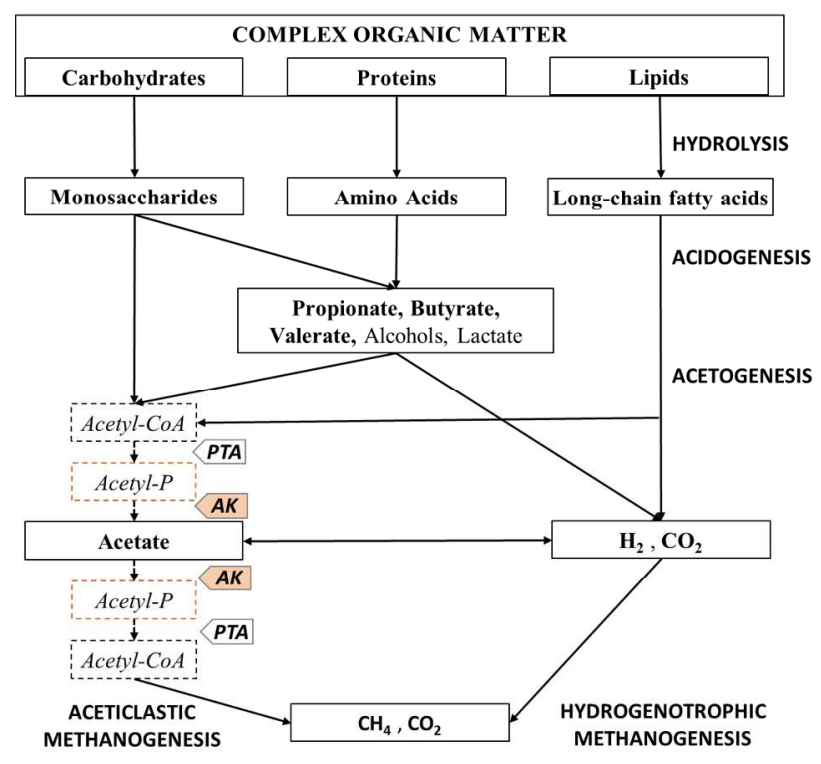

96 Figure 1. Schematic representation of the steps of anaerobic digestion, including the roles of the

97 enzymes acetate kinase (AK) and phosphotransacetylase (PTA).

98 The major aim of this work was to gain insight into the biotransformation pathways involved

99 in the removal of OMPs during methanogenesis. In particular, the enzymatic transformation of

100 OMPs was assessed via in vitro assays with AK. Furthermore, the cometabolic impact of AK on

101 the biotransformation of OMPs in methanogenic reactors (MRs) was quantified. To the best of

102 our knowledge, this is the first attempt to clarify the role of $\mathrm{AD}$ enzymes on the

103 biotransformation of OMPs.

\section{MATERIALS AND METHODS}

105 Organic micropollutants. This study focuses on 20 compounds that are commonly

106 detected in sewage sludge $e^{3,4,8,9,31-33}$ and whose chemical structures (Table S1), applications and

107 physicochemical properties (Table S2) are representative of a huge range of OMPs. The selected

108 pollutants are: the musk fragrances galaxolide (HHCB), tonalide (AHTN) and celestolide

109 (ADBI); the anti-inflammatories ibuprofen (IBP), naproxen (NPX) and diclofenac (DCF); the 
110 antibiotics sulfamethoxazole (SMX), trimethoprim (TMP), erythromycin (ERY) and

111 roxithromycin (ROX); the neurodrugs fluoxetine (FLX), carbamazepine (CBZ) and diazepam

112 (DZP); and the endocrine-disrupting compounds triclosan (TCS), bisphenol A (BPA), 4-

113 octylphenol (OP), 4-nonylphenol (NP), estrone (E1), 17 $\beta$-estradiol (E2) and 17 $\alpha$-ethinylestradiol

114 (EE2). These substances were purchased from Sigma-Aldrich (Steinheim, Germany) except for

115 the fragrances, which were provided by Ventos (Spain). Stock solutions were prepared in HPLC

116 grade methanol or acetone, depending on the compound, and stored at $-18{ }^{\circ} \mathrm{C}$.

117 Methanogenic reactor. Two lab-scale (14 L) continuously stirred (IKA RW20, $150 \mathrm{rpm}$ )

118 MRs were operated under mesophilic $\left(37^{\circ} \mathrm{C}\right)$ conditions. Both reactors were inoculated with

119 sludge from a mesophilic STP anaerobic digester. The feeding consisted of a synthetic mixture of

120 volatile fatty acids (VFA) (acetic:butyric:propionic 50:25:25, \%COD) and other trace nutrients

121 (section S4), in order to promote the growth of acetogenic bacteria and aceticlastic methanogenic 122 archaea (i.e. Methanosaeta and Methanosarcina). ${ }^{15,34,35}$ After a start-up period, both MRs

123 reached steady-state operation at a hydraulic retention time (HRT) of $10 \mathrm{~d}$, an organic loading 124 rate (OLR) of $1 \mathrm{~g} \mathrm{COD} \mathrm{L}^{-1} \mathrm{~d}^{-1}$ and a methanization efficiency above $70 \%$. After $1-2$ months 125 under these conditions (Table S4), a pulse of the selected OMPs $\left(100 \mu \mathrm{g} \mathrm{L}^{-1}\right.$ except for the 126 hormones, which were $10 \mu \mathrm{g} \mathrm{L}^{-1}$, section S4) was added to each MRs, and their concentrations 127 were followed in the liquid (17 samples) and solid (10 samples) phases for $10 \mathrm{~d}$.

128 Acetate kinase activity. Acetate kinase (AK, EC 2.7.2.1) is a homodimer with two active 129 sites that catalyze the reversible Mg-dependent transfer of the $\Upsilon$-phosphoryl group from 130 adenosine triphosphate (ATP) to acetate. ${ }^{27}$ AK from Methanosarcina thermophila was chosen 131 for this study because it is a well characterized and investigated enzyme ${ }^{29}$ and because 132 Methanosarcina species appear to be key organisms in $\mathrm{AD} .{ }^{36} \mathrm{AK}$ from $M$. thermophila 
133 recombinant, expressed in E. coli, was purchased from Sigma-Aldrich (USA) as lyophilized 134 powder (885 $\mathrm{U} \mathrm{mg}^{-1}$ protein (Bradford) and $6.94 \mathrm{U} \mathrm{mg}^{-1}$ solid). One unit (U) phosphorylates $1351.0 \mu \mathrm{mol}$ of acetate to acetyl phosphate per min at $\mathrm{pH} 7.6$ and $25^{\circ} \mathrm{C}$. The $\mathrm{AK}$ powder was stored 136 at $-20{ }^{\circ} \mathrm{C}$. Immediately before use, a solution of $\mathrm{AK}\left(288 \mu \mathrm{g} \mathrm{mL}-1,2.0 \mathrm{U} \mathrm{mL}^{-1}\right)$ in a potassium 137 phosphate buffer (0.1 M, pH 7.4) was prepared.

138 Hydroxamate assay. The hydroxamate assay ${ }^{37,38}$ is the simplest and most convenient method 139 to determine the AK activity in the direction of acetyl phosphate synthesis. ${ }^{29}$ This standard assay 140 measures the rate of the forward Reaction 1 in the presence of hydroxylamine, which reacts with 141 acetyl phosphate (Reaction 2) to form a colored complex in the presence of trivalent iron 142 (Reaction 3). Under standard conditions, dephosphorylate acetyl phosphate is thermodynamically 143 more favorable (Reaction 1); therefore, hydroxylamine is required to shift the reaction 144 equilibrium to the right through the removal of acetyl phosphate. ${ }^{37}$

$145 \quad$ Acetate + ATP $\stackrel{A K}{\longleftrightarrow}$ Acetyl-P + ADP (Reaction 1)

146 Acetyl-P + Hydroxylamine $\rightarrow$ Acetyl hydroxamate $+\mathrm{HPO}_{4}{ }^{2-}$ (Reaction 2)

$147 \quad$ Acetyl hydroxamate $+\mathrm{FeCl}_{3} \rightarrow$ Ferric acetylhydroxamate (Reaction 3)

148 An adaptation of the hydroxamate assay $^{30}$ was used in this study. A stock solution was 149 prepared with the following components: $290 \mathrm{mM}$ of Tris- $\mathrm{HCl}(\mathrm{pH} 7.4$, neutralized with $\mathrm{KOH}$ ), $150400 \mathrm{mM}$ of potassium acetate, $20 \mathrm{mM}$ of $\mathrm{MgCl}_{2} \cdot 6 \mathrm{H}_{2} \mathrm{O}, 20 \mathrm{mM}$ of ATP and $1410 \mathrm{mM}$ of 151 hydroxylamine hydrochloride ( $\mathrm{pH} 7.4$, neutralized with $\mathrm{KOH}$ ). This reaction mixture was 152 prepared immediately before use, since the aqueous solution of ATP at room temperature and the 153 neutralized hydroxylamine solution have a limited stability. The reaction started by adding $1541.0 \mathrm{~mL}$ of the enzyme solution over $1.0 \mathrm{~mL}$ of the pre-warmed $\left(25^{\circ} \mathrm{C}\right)$ reaction mixture. After 
155 incubation for $12 \min$ at $25^{\circ} \mathrm{C}$, the reaction was stopped by the addition of $2.0 \mathrm{~mL}$ of $10 \%$ 156 trichloroacetic acid. Then, the color reaction was initiated by adding $2.0 \mathrm{~mL}$ of $\mathrm{FeCl}_{3}(2.5 \%$ in $1572 \mathrm{~N} \mathrm{HCl}$ ). After 5-30 min of incubation to allow for the formation of the colored complex, ${ }^{38}$ the 158 absorbance was recorded spectrophotometrically (Cecil CE-7200, UK) at $540 \mathrm{~nm}$.

159 A standard curve was prepared by adding $0-1.7 \mathrm{U} \mathrm{mL}^{-1}$ of $\mathrm{AK}$ to the reaction mixture 160 following the previously described methodology (Figure S2). Furthermore, because $1 \mathrm{U}$ of 161 enzyme dephosphorylates $1 \mu \mathrm{mol}$ of ATP per minute, the consumption of ATP $\left(\mu \mathrm{mol} \mathrm{mL}^{-1}\right)$ can 162 also be correlated with the measured absorbance (Equation S1).

163 AK activity in the methanogenic reactor. The $\mathrm{AK}$ activity inside the reactor was 164 determined without special precautions to avoid the presence of air (AK is not sensitive to 165 oxygen $)^{30,39}$ following a methodology adapted from $\mathrm{Mu}$ et al. ${ }^{40}$ Three samples $25 \mathrm{~mL}$ were 166 withdrawn at different time points after the OMPs spike (10 min, $3 \mathrm{~d}$ and $10 \mathrm{~d})$ and then 167 centrifuged at $3107 \mathrm{~g}$ for $15 \mathrm{~min}$. The supernatant was discarded, and the biomass was washed 168 and resuspended in $25 \mathrm{~mL}$ of $0.1 \mathrm{M}$ sodium phosphate buffer $(\mathrm{pH} 7.4)$. This procedure was 169 repeated three times. The last resuspended mixture was sonicated at $20 \mathrm{kHz}$ and $4{ }^{\circ} \mathrm{C}$ for $10 \mathrm{~min}$ 170 to break down the cell walls and release the intracellular AK. The sample was then centrifuged at $171 \quad 15344 \mathrm{~g}$ and $4{ }^{\circ} \mathrm{C}$ for $30 \mathrm{~min}$ to remove the waste debris. When needed, the extracts were stored 172 at $-20^{\circ} \mathrm{C}$ before measuring the enzyme activity assay via the hydroxamate assay.

173 Experiments with commercial AK. Preliminary assays. The relevance of several key 174 parameters (temperature, $\mathrm{pH}$ and OMPs concentration) on the AK activity was first evaluated 175 because they could impair the possible action of AK over the OMPs. Studies with AK from $M$. 176 thermophila have typically been performed at $37^{\circ} \mathrm{C},{ }^{27,30,41,42}$ but the product information from 177 SIGMA recommends a temperature of $25^{\circ} \mathrm{C}$ for the enzymatic assay. Therefore, several 
178 theoretical AK activities $\left(0.01,0.05,0.2 \mathrm{U} \mathrm{mL}^{-1}\right)$ were evaluated via the hydroxamate assay at 179 both temperatures. The results did not show significant differences (Table S5); thus, the lower 180 temperature $\left(25^{\circ} \mathrm{C}\right)$ was chosen for the next assays to minimize possible activity losses by 181 enzyme denaturation in long-term experiments. ${ }^{43}$

182 A similar procedure was followed for the $\mathrm{pH}$ selection. According to Aceti and Ferry ${ }^{30}$ and 183 the product information from SIGMA, the maximum activity of AK appears between $\mathrm{pH}$ 7.0-7.6. 184 Both extreme pHs were tested and, as expected, the effect on the AK activity $\left(0.02 \mathrm{U} \mathrm{mL}^{-1}\right) \mathrm{was}^{-}$ 185 negligible (Table S5). To prevent the $\mathrm{pH}$ from decreasing below 7.0 during the OMP assays due 186 to the consumption of acetate (weak base), the initial $\mathrm{pH}$ was adjusted with $\mathrm{KOH}$ to 7.6.

187 Finally, a possible inhibition of the AK activity by the OMPs was examined at 3 OMPs/AK 188 ratios: $0.35 \mu \mathrm{g} \mathrm{mg}^{-1}\left(50 \mu \mathrm{g} \mathrm{OMPs} \mathrm{L}{ }^{-1}\right.$ and $\left.144 \mathrm{mg} \mathrm{AK} \mathrm{L}^{-1}\right), 3.5 \mu \mathrm{g} \mathrm{mg}^{-1}\left(100 \mu \mathrm{g} \mathrm{OMPs} \mathrm{L}{ }^{-1}\right.$ and $\left.18928.8 \mathrm{mg} \mathrm{AK} \mathrm{L}^{-1}\right)$ and $69 \mu \mathrm{g} \mathrm{mg}^{-1}\left(100 \mu \mathrm{g} \mathrm{OMPs} \mathrm{L}^{-1}\right.$ and $\left.1.44 \mathrm{mg} \mathrm{AK} \mathrm{L}^{-1}\right)$. In all cases, a negative 190 control without OMPs was included. The results (Table S5) indicated that AK activity was not 191 altered by any OMPs/AK ratio tested, and thus neither by the corresponding solvents added with 192 the OMPs pulse. The OMPs/AK ratio employed in the OMPs assays was $35 \mu \mathrm{g} \mathrm{mg}^{-1}$ (based on 193 the theoretical AK activity of a mesophilic AD operating at an OLR of $2 \mathrm{~g} \mathrm{COD} \mathrm{L}^{-1} \mathrm{~d}^{-1}$ with a $19470 \%$ methanization efficiency).

195 Enzymatic transformation of OMPs. Once the operating parameters were selected $\left(25^{\circ} \mathrm{C}\right.$, $196 \mathrm{pH} 7.6,100 \mu \mathrm{g} \mathrm{L}^{-1}$ of OMPs and $2.9 \mathrm{mg} \mathrm{L}^{-1}$ of $\left.\mathrm{AK}\right)$, the enzymatic transformation of the OMPs 197 was evaluated at two reaction times ( $1 \mathrm{~d}$ and $5 \mathrm{~d})$ with and without the primary substrate (acetate) 198 in duplicate in $100 \mathrm{~mL}$ Erlenmeyer flasks. The final reaction media contained $145 \mathrm{mM}$ of Tris$199 \mathrm{HCl}, 10 \mathrm{mM}$ of $\mathrm{MgCl}_{2} \cdot 6 \mathrm{H}_{2} \mathrm{O}, 705 \mathrm{mM}$ of hydroxylamine hydrochloride, $200 \mathrm{mM}$ of potassium 200 acetate (in excess) and $50 \mathrm{mM}$ of ATP. The acetate concentration, ATP consumption (Equation 
201 S1), AK activity, $\mathrm{pH}$ and temperature were monitored $(\mathrm{n}=2)$ at different reaction times $(5-11$ 202 time points) and the concentration of OMPs was measured in replicate at the beginning ( $\mathrm{n}=4)$ and 203 end $(n=4)$ of each experiment.

204 Abiotic disappearance of OMPs. The disappearance of the parent micropollutants by 205 adsorption was evaluated by comparing the concentration of OMPs $\left(100 \mu \mathrm{g} \mathrm{L}^{-1}\right.$ in distilled 206 water) after $1 \mathrm{~d}$ at $25^{\circ} \mathrm{C}$ in contact with $\mathrm{AK}\left(2.9 \mathrm{mg} \mathrm{L}^{-1}\right)$ and without the enzyme. No 207 representative differences were found (data not shown), so the adsorption of OMPs during the 208 enzymatic assays with commercial AK was dismissed. Furthermore, to discard possible losses of 209 the parent compound by evaporation, analytical difficulties or chemical reaction with the media 210 (145 mM of Tris-HCl, $10 \mathrm{mM}$ of $\mathrm{MgCl}_{2}, 705 \mathrm{mM}$ of hydroxylamine hydrochloride, $50 \mathrm{mM}$ of 211 ATP, $200 \mathrm{mM}$ of potassium acetate), duplicated negative controls (without AK) were incubated 212 under the same conditions as the AK assays specified in the previous section. Trichloroacetic 213 acid was not used to stop the enzymatic activity at the end of the assays with OMPs because 214 reductions of the concentrations of ERY, ROX and SMX were observed when it was added. The 215 enzymatic reaction was assumed to stop once the solid phase extraction (SPE) was performed.

216 Analytical methods. Conventional parameters. The operation of the methanogenic 217 digesters was monitored in terms of the temperature, $\mathrm{pH}$, total suspended solids (TSS), volatile 218 suspended solids (VSS), alkalinity, ammonium, and total and soluble COD. ${ }^{44}$ Biogas production 219 was recorded using Ritter milligas counters (Dr. Ing. Ritter Apparatebau GmbH, Bochum, 220 Germany), and its composition was determined through gas chromatography (HP 5890 Series II). 221 Volatile fatty acids (VFA) were measured individually in a gas chromatograph (HP 5890A) 222 equipped with a flame ionization detector (HP 7637A). 
223 Organic micropollutants analysis. Samples from the MRs were centrifuged at $1880 \mathrm{~g}$ for

$22415 \mathrm{~min}$. The supernatant was pre-filtered (AP4004705, Millipore) and filtered at $0.45 \mu \mathrm{m}$

225 (HAWP04700, Millipore) before performing the SPE with $100 \mathrm{~mL}$ samples and $60 \mathrm{mg}$ OASIS

226 HLB cartridges (Waters, Milford, MA, USA). ${ }^{4,16}$ Samples from the enzymatic assays (50 $\left.\mathrm{mL}\right)$

227 did not require any pre-treatment prior to SPE. To quantify the OMPs sorbed onto the 228 methanogenic sludge, ultrasonic solvent extraction (USE) was conducted before SPE, as

229 described by Gonzalez-Gil et al. ${ }^{4}$ The limits of quantification (LOQ) and recoveries applied to 230 the MRs and the AK assays are shown in Table S3.

231 Statistical analysis. All of the enzymatic assays with OMPs were conducted in duplicate,

232 and each micropollutant concentration was measured twice $(n=4)$. The results are expressed as

233 mean \pm standard deviation. The significant differences between the enzymatic results were

234 statistically tested by analysis of variance (ANOVA) followed by the Dunnett T3 test for

235 multiple comparisons. The normal data distribution was analyzed with the Shapiro-Wilk test, and

236 the variance homogeneity was analyzed with the Levene test. When the variances were not

237 homogeneous, Brown-Forysthe analysis was used to assess the significant differences. All of the 238 statistical tests were performed at a 5\% significance level using the IBM SPSS statistics ${ }^{\circledR}$ 239 software 20.0.

\section{RESULTS AND DISCUSSION}

241 Biotransformation of OMPs during methanogenesis. Figure 2 aims to highlight, in a

242 semi-quantitative representation, the relevance of the methanogenic step on the overall removal

243 efficiencies reported for OMPs during AD of sewage sludge. The methanogenic biomass showed

244 the capacity to biotransform all of the tested OMPs, although the efficiencies varied depending 
245 on the compound. For example, SMX, NPX, TMP, OP, NP, FLX, EE2, TCS and the musk

246 fragrances were significantly removed during methanogenesis, while the other compounds had

247 biotransformations of less than $50 \%$.

248 It was not easy to get a single value for the removal of OMPs during AD process due to the 249 divergences on the reported values. Trying to narrow these differences, the average AD removals 250 depicted on Figure 2 correspond to studies that used mainly continuous mesophilic digesters, 251 treating sewage sludge at a HRT between 10 and $30 \mathrm{~d}$ (Table S6). Even though, IBP, DCF, BPA, 252 NP, FLX, the hormones and the musk fragrances still presented high deviations, so it was not 253 possible to accurately determine the influence of the methanogenesis on their disappearance. 254 Most of the OMPs appear near the diagonal (between the two dashed lines) of Figure 2, 255 suggesting that the methanogenic biomass is the main responsible for their biotransformation 256 during AD. Therefore, the action of key enzymes participating in the methanogenic route, 257 particularly AK, were further investigated in the next sections. ROX and TMP are the only 258 compounds that clearly showed a higher removal during the overall AD, which indicates that 259 other anaerobic communities (i.e., hydrolytic and acidogenic) widely participate on their 260 removal. 


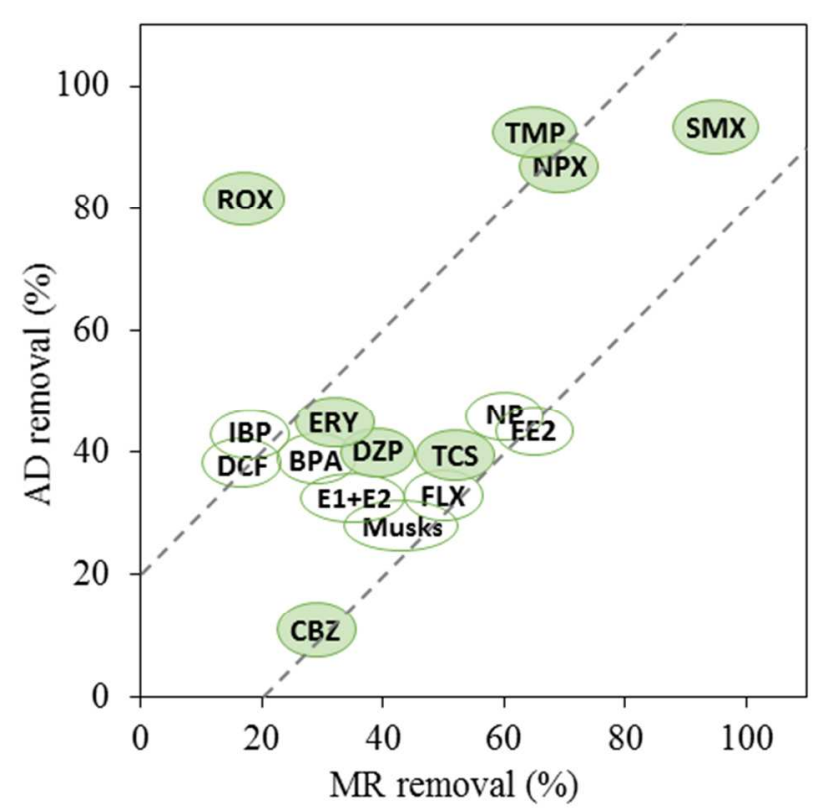

Figure 2. Semi-quantitative representation of the removal efficiencies of OMPs in the

263 methanogenic reactors (MR, $\mathrm{x}$-axis) versus the average removal during $\mathrm{AD}$ of sewage sludge $\mathrm{e}^{4,8-}$

$264^{12,45-47}$ (y-axis). Compounds with large divergences on the reported AD removals (standard

265 deviations above 25\%) are depicted by open ellipses. No data about the removal of OP in AD

266 was found $(60-70 \%$ in the MRs). The two dashed lines delimit the region where methanogenesis

267 explains to a high extent the overall AD removal of the OMPs.

268 Transformation of OMPs in the AK assays. The experiments were performed at two

269 reaction times ( 1 and 5 days) and, with the exception of the negative control in the absence of

$270 \mathrm{AK}$, consisted of two assays with and without acetate, which were intended to assess the role of

271 the main substrate on the possible AK catalytic transformation of OMPs. No significant

272 differences were found between the negative control and the two AK assays in the 1-day

273 experiment (data not shown), likely because the reaction time was not sufficient to illustrate the

274 action of AK on OMPs. Hence, this section focuses on the 5-day assays. 
Performance of assays. The ATP and acetate concentrations during the 5-day assay are

276 shown in Figure 3. The AK activity during the first $2 \mathrm{~d}$ was $4.8 \pm 0.2 \mathrm{U} \mathrm{L}^{-1}$, which resulted in a

277 moderate conversion of acetate and ATP (approximately 30\%). To increase the enzymatic

278 activity, a second pulse of AK $\left(8.6 \mathrm{mg} \mathrm{L}^{-1}\right)$ and ATP $(40 \mathrm{mM})$ was added to the reaction media

279 after $52 \mathrm{~h}$. As a result, more rapid acetate and ATP consumption was achieved (Figure 3), which

280 led to an average AK activity of $13.4 \pm 1.5 \mathrm{U} \mathrm{L}^{-1}$. After approximately $4 \mathrm{~d}$, the depletion of both

281 reagents almost stopped, which suggests that the phosphorylation of acetate (Reaction 1) reached

282 an equilibrium. This is likely due to the decomposition of hydroxylamine at room temperature in

283 neutralized solutions, ${ }^{38,48}$ which is required to perform Reaction 2 and thus to avoid equilibrium

284 of Reaction 1. This hypothesis is also supported by the fact that the acetate concentration on day

2855 was higher than the value that was estimated stoichiometrically from the ATP consumption

286 rates (Figure 3). The average AK activity during the 5-day assay with acetate was much higher

$287\left(8.0 \mathrm{U} \mathrm{L}^{-1}\right)$ than in the assay without acetate $\left(0.1 \mathrm{U} \mathrm{L}^{-1}\right)$, where a considerably lower conversion

288 of ATP ( $2 \%$ after $5 \mathrm{~d}$ ) was also achieved because the only potential substrates for AK are OMPs

289 at a much lower concentration than the acetate.

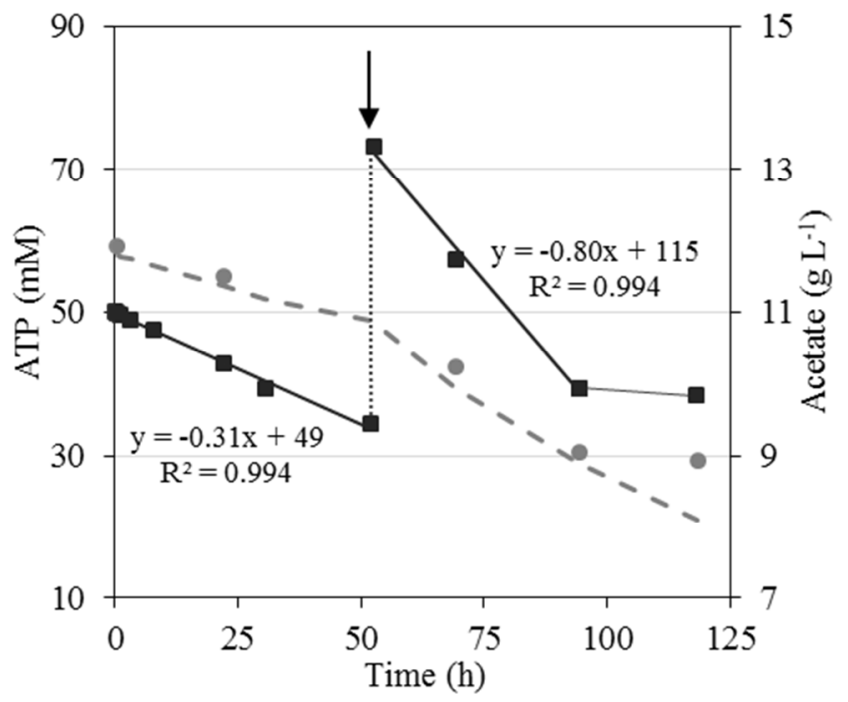


291 Figure 3. ATP (limiting reagent; squares) and acetate (dots) concentrations in the 5-day AK 292 assay with acetate. The arrow indicates the second addition of ATP and AK. The dashed line 293 represents the stoichiometric acetate concentration considering the consumption rates of ATP.

294 Chemical OMP transformation. The initial concentration of OMPs in distilled water is 295 compared to the concentration of OMPs after $5 \mathrm{~d}$ in the negative control (reaction media without 296 AK) in Figure 4. DZP, AHTN, ADBI, ERY, E1, EE2 and CBZ nearly completely disappear, 297 likely due to the reaction between the ketone group of these compounds (except EE2) with the 298 hydroxylamine required to perform the enzymatic assays. This hypothesis was confirmed 299 experimentally because the OMPs concentration did not decrease in a reaction media without this 300 amine. However, hydroxylamine was included in the reaction media to shift the action of AK 301 towards acetate phosphorylation (Reaction 1). Obviously, this decision masks any possible effect 302 of AK on the biotransformation of these seven OMPs. 


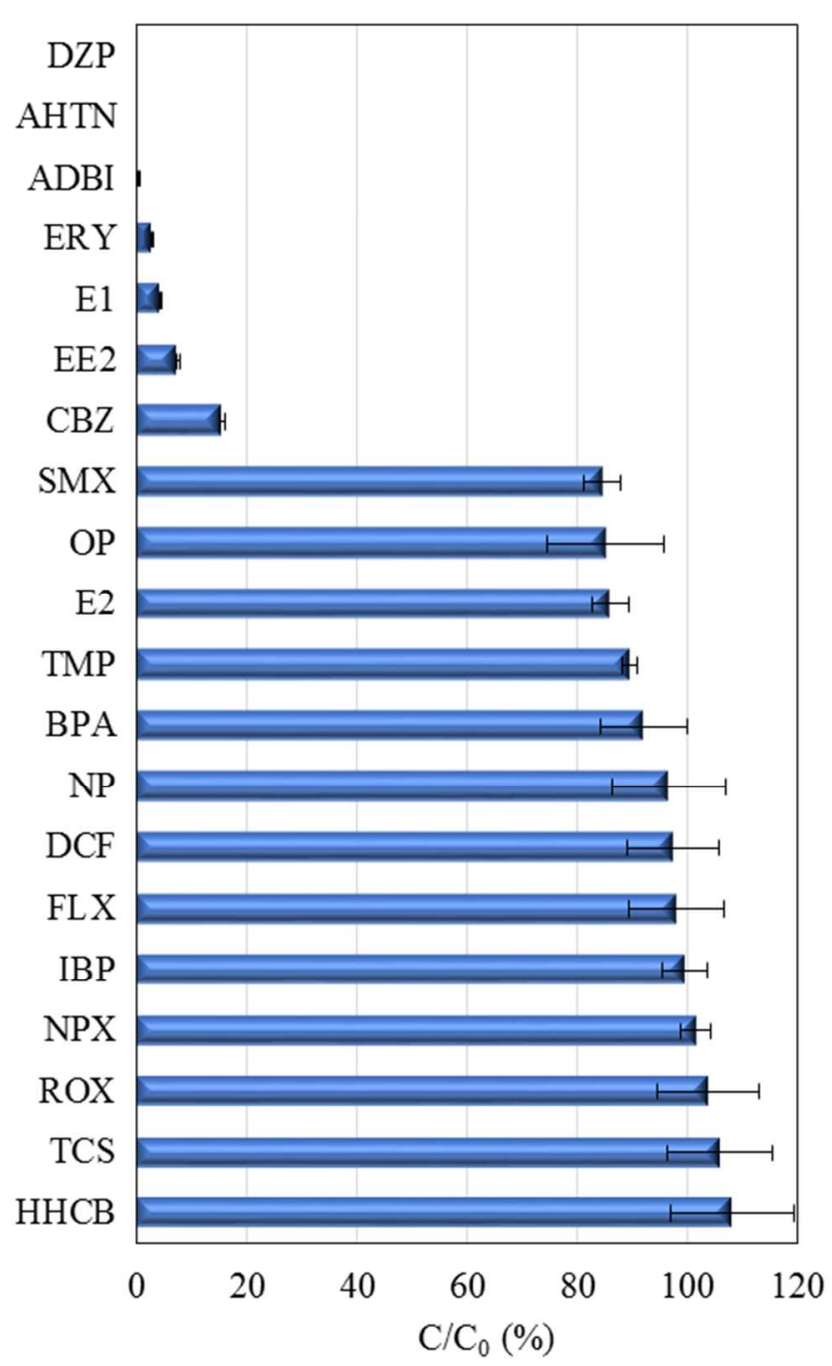

304 Figure 4. Chemical transformation of OMPs expressed as the ratio between the concentration in 305 the negative control (reaction media without enzyme) after $5 \mathrm{~d}(\mathrm{C})$ to the initial concentration in 306 distilled water $\left(\mathrm{C}_{0}\right)$.

307 Enzymatic transformation. The concentrations of the 13 OMPs that were not chemically 308 transformed in the negative control after the 5-day assays with AK are shown in Figure 5. Based 309 on their chemical structures (Table S1), these compounds are classified into three groups. The 310 first group includes carboxylic compounds (IBP, NPX, DCF), the second group are OMPs with 311 hydroxyl groups (NP, OP, BPA, TCS, ROX, E2), and the third group comprises compounds with 
312 other functional groups (HHCB, SMX, TMP, FLX). All data were normally distributed and, 313 except for NPX, OP and HHCB, their variances were homogeneous. FLX, TMP, SMX, E2 and

314 ROX were not affected by AK, since no significant differences were found between the negative

315 control and both enzymatic assays (with and without acetate). In contrast, this difference was

316 statistically significant $(\mathrm{p}<0.05)$ for IBP, NPX, DCF, NP, OP, BPA, TCS and HHCB proving

317 that these 8 compounds are transformed by the action of the enzyme. No statistical differences

318 were found between the concentrations of these 8 OMPs in the AK assays performed in the

319 presence and absence of acetate, which suggests that no competitive inhibition occurred between

320 the primary substrate (acetate) and the cometabolic substrates (OMPs). ${ }^{19,20}$ Moreover, these

321 results suggest that once $\mathrm{AK}$ is available it can directly transform OMPs in the absence of

322 acetate. However, the presence of the primary substrate is needed to trigger the synthesis of AK

323 during the AD process; therefore, according to the definition of cometabolism, ${ }^{17,20,21}$ the

324 transformation of OMPs (non-growth substrates) is fortuitous and inherently linked to acetate.

325 To understand how AK can transform these compounds, it is necessary to look into the AK 326 specificity. The action of AK from M. thermophila is quite restrictive because the size of the

327 hydrophobic pocket and its affinity to the methyl group of acetate are determinant for substrate

328 specificity. ${ }^{42}$ However, this enzyme still shows slight activity over larger substrates with

329 carboxyl groups (propionate, butyrate), alcohols (ethanol) and even over compounds without

330 hydrophobic groups (formate, glycerol, glycine, glycolic acid). ${ }^{29,30}$ For that reason, IBP, NPX

331 and DCF, which have a carboxyl group (Group 1, Table S1) and are relatively small (1-2

332 benzene rings), were significantly $(\mathrm{p}<0.05)$ biotransformed by AK $(10-15 \%)$. In addition,

333 compounds with hydroxyl groups in their chemical structure (Group 2, Table S1) could also be

334 appropriate substrates for AK. Nevertheless, the molecular size appears to be determinant 
335 because only the smaller compounds (NP, OP, BPA and TCS) were biotransformed (15-32\%).

336 The steric hindrance of ROX and E2 could hinder the formation of the enzyme-substrate 337 complex and their further reaction. Similarly, ERY, EE2 and E1, which reacted chemically with 338 the hydroxylamine, would not be affected by AK due to their large molecular size. As expected, 339 the concentrations of the rest of the OMPs (Group 3, Table S1) did not decrease during the 340 enzymatic assays, excluding HHCB (45-50\%), for which a clear explanation was not found. It is

341 hypothesized that AK could attack the ether group of this compound, but no references were 342 found to support this enzymatic transformation. 


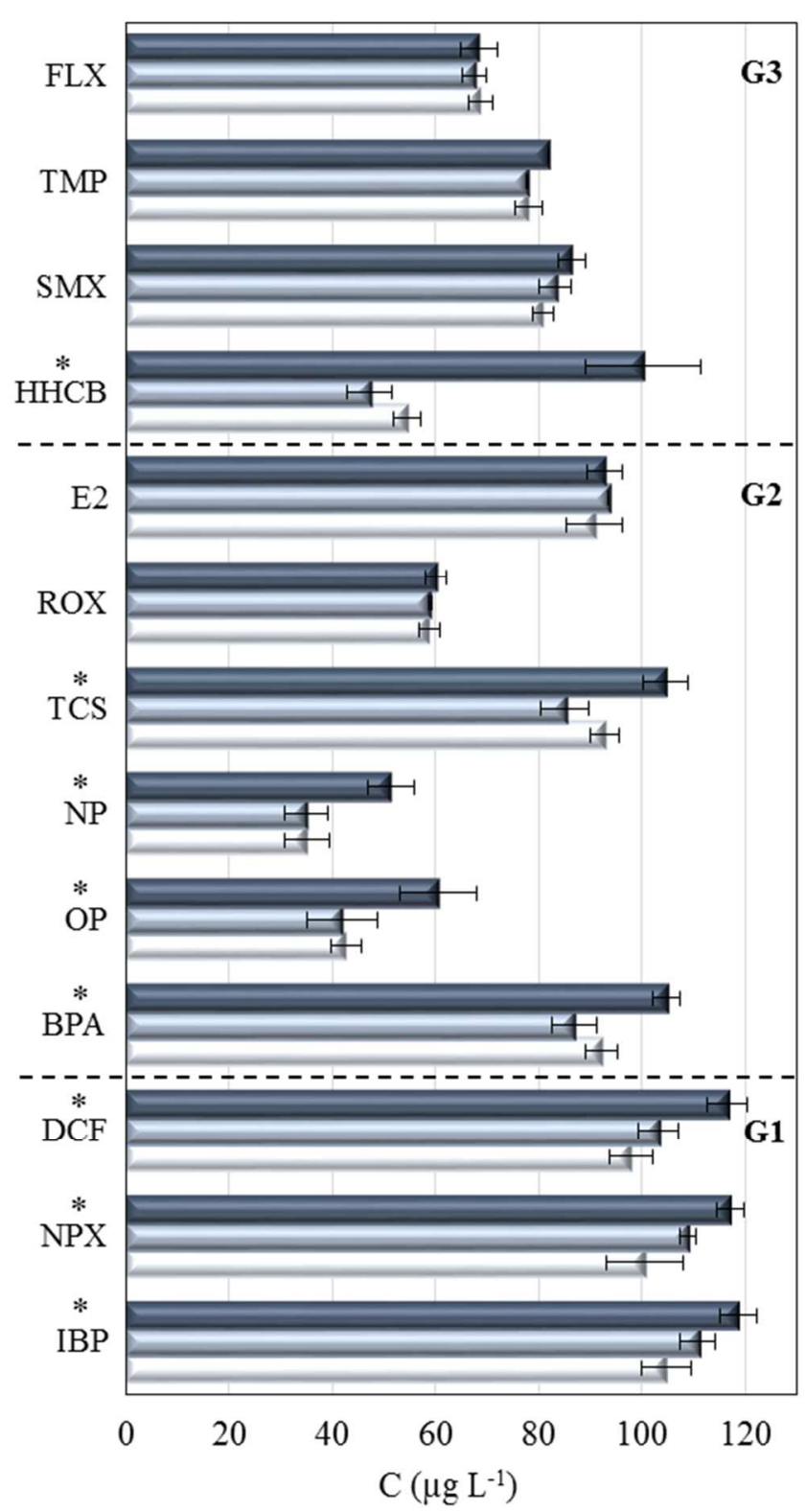

345 Figure 5. Transformation of OMPs by AK after 5 days of reaction time. The dark bars represent

346 the concentrations of OMPs in the negative control (reaction media without enzyme), the light

347 bars refer to the assay with acetate, and the white bars refer to the assay without acetate. The

348 asterisks indicate the statistical differences $(\mathrm{p}<0.05)$ of both AK assays with respect to the

349 control. The compounds are sorted according to their chemical structures in three groups: (G1)

350 OMPs with a carboxyl group, (G2) OMPs with a hydroxyl group and (G3) OMPs with other

351 functional groups. 
352 The results of these experiments demonstrate the importance of combining the specificity of 353 the enzymes and the chemical structure of OMPs to understand the biotransformation 354 mechanisms. Accordingly, we hypothesized that some of the evaluated OMPs (Figure 5) are 355 enzymatically transformed by the cometabolic action of AK when ATP is available in the media 356 and disregarding the presence of the primary substrate (acetate). The proposed pathway predicts 357 the formation of phosphorylated TPs. For example, the carboxyl group of NPX could act as the 358 acceptor of a phosphoryl group, as occurs with acetate (Figure 6). Because the detection and 359 identification of TPs is very challenging, a deep understanding of the cometabolic enzymatic 360 biotransformation of OMPs allows TPs to be predicted, as was revealed in this study.

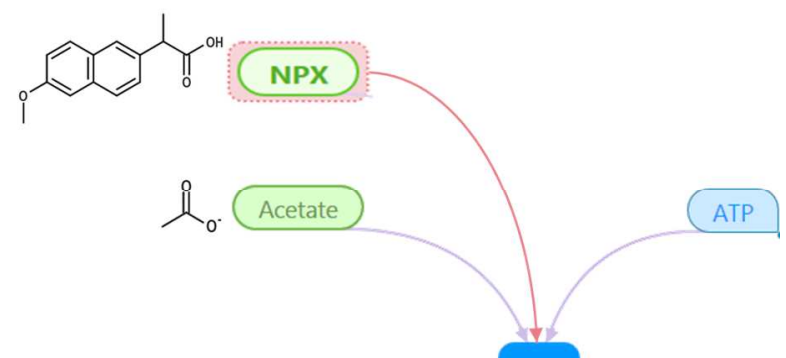

362 Figure 6. Proposed cometabolic pathway for the biotransformation of some OMPs, such as 363 NPX, by the enzyme AK during methanogenesis. cometabolically phosphorylate compounds with carboxyl or hydroxyl groups and relatively low

367 steric hindrance, such as IBP, NPX, DCF, NP, OP, BPA and TCS. Therefore, the next step is to 
368 determine the relevance of this mechanism to the overall biotransformation that was observed for

369 the aforementioned OMPs in the MRs. Figure 7 compares the biotransformation rates $\left(\mu \mathrm{g} \mathrm{L}^{-1} \mathrm{~d}^{-1}\right)$

370 that were obtained in the AK assays with acetate and in the MRs at the same reaction time (5 d).

371 It is important to note that the AK activities in the MRs and the enzymatic assay are quite similar

372 (7.0 and $8.0 \mathrm{U} \mathrm{L}^{-1}$, respectively). Assuming that $2 / 3$ of the total $\mathrm{CH}_{4}$ is produced from acetate by

373 aceticlastic archaea, ${ }^{26}$ the theoretical AK activity in the MRs (OLR of $1 \mathrm{~g} \mathrm{COD} \mathrm{L}^{-1} \mathrm{~d}^{-1}$ and $70 \%$

374 methanization would be $10 \mathrm{U} \mathrm{L}^{-1}$, which is similar to the measured value.

375 Depending on the compound, the biotransformation rates in the MRs varied from 3.0 to $37614 \mu \mathrm{g} \mathrm{OMP} \mathrm{L}^{-1} \mathrm{~d}^{-1}$, while this range is narrower in the AK assays $\left(1.5-4.0 \mu \mathrm{g} \mathrm{OMP} \mathrm{L}^{-1} \mathrm{~d}^{-1}\right)$. IBP

377 and DCF are hardly biotransformed during methanogenesis (3.0-3.5 $\mu \mathrm{g}$ OMP L $\mathrm{L}^{-1}$ ), although 378 an important removal mechanism $(>45 \%)$ is related to AK action. The AK cometabolic 379 mechanism is also relevant $(61 \%)$ in the methanogenic biotransformation of BPA $\left(6 \mu \mathrm{g} \mathrm{OMP} \mathrm{L}^{-}\right.$

$\left.380{ }^{1} \mathrm{~d}^{-1}\right)$. In contrast, the transformation of NPX by AK (12\%) does not explain its high depletion 381 during methanogenesis (14 $\mu \mathrm{g}$ OMP L $\left.\mathrm{L}^{-1} \mathrm{~d}^{-1}\right)$. Likewise, AK accounts for only $28-38 \%$ of the 382 overall biotransformation observed for OP, NP and TCS in the MRs $\left(10-13 \mu \mathrm{g} \mathrm{OMP} \mathrm{L}^{-1} \mathrm{~d}^{-1}\right)$. On 383 the other hand, AK would explain the whole biotransformation rate of $\mathrm{HHCB}$ in the MR 384 (9 $\left.\mu \mathrm{g} \mathrm{OMP} \mathrm{L}^{-1} \mathrm{~d}^{-1}\right)$; what is a quite surprising fact, especially because it cannot be ascertain that 385 this transformation occurs via the proposed cometabolic phosphorylation pathway.

386 Based on these results, no direct relationship was found between the degree of 387 biotransformation during methanogenesis and the contribution of the $\mathrm{AK}$ cometabolic 388 mechanism. Moreover, the biotransformation rate was always higher in the MRs, which suggests 389 that other active enzymes in addition to AK could further transform them. Some candidate 390 enzymes could be those that continue the aceticlastic methanogenesis (Figure S1), those involved 
391 in the hydrogenotrophic methanogenesis ${ }^{49}$ or other kinases, such as propionate and butyrate 392 kinase. These two kinases have a larger hydrophobic pocket than AK to directly phosphorylate

393 propionate and butyrate, respectively; ${ }^{50,51}$ therefore, they could be involved in the enzymatic 394 transformation of the same OMPs as AK, but they could also promote the transformation of 395 larger OMPs with hydroxyl groups, such as ERY, ROX, E1, E2 and EE2, which were not 396 affected by AK. Otherwise, the high methanogenic biotransformations of TMP and SMX (Figure 397 2) should be caused by other types of enzymes because kinases will not modify their chemical 398 structure. In summary, by combining enzyme action and the OMP's chemical structure, new 399 insights are provided to understand the transformation mechanisms of OMPs during AD, which 400 is useful for developing new strategies to maximize the elimination of OMPs from sewage 401 sludge and to predict the TPs that form and their potential risks.

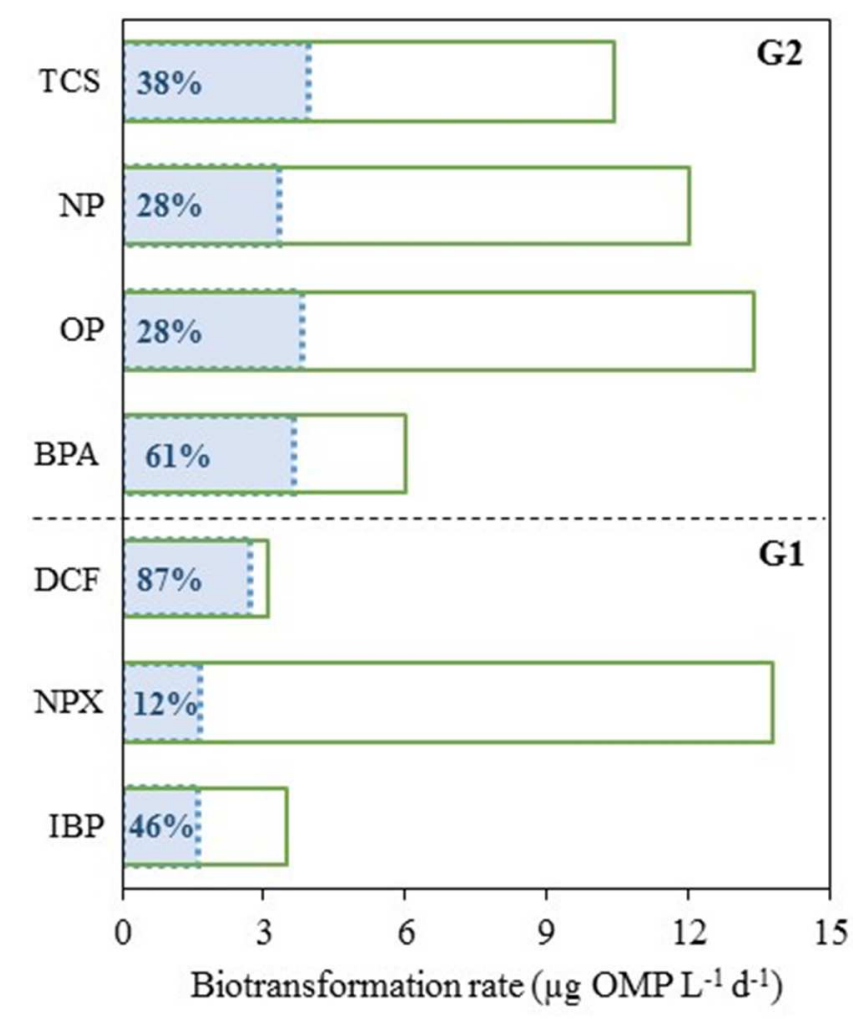


403 Figure 7. Biotransformation rates of the OMPs prone to be cometabolically phosphorylated by 404 AK in the MRs (empty green bars) and in the AK assay with acetate (blue-pointed bars) after 5 405 days. The percentages indicate the contribution of $\mathrm{AK}$ to the methanogenic biotransformation. 406 G1 refers to OMPs with carboxylic compounds, and G2 refers to OMPs with hydroxyl groups. 407 HHCB was excluded from this figure due to the lack of information regarding the 408 phosphorylation action of AK on ether groups. 


\section{ASSOCIATED CONTENT}

\section{Supporting Information}

411 The Supporting Information is available free of charge on the ACS Publications website.

412 Enzymatic pathways of the aceticlastic methanogenesis (Figure S1); chemical structures (Table

413 S1) and physicochemical properties (Table S2) of the OMPs; limits of quantification and 414 recoveries of the analytical methods (Table S3); details of the MRs performance (section S4, 415 Table S4); details of the acetate kinase activity determination (section S5, Figure S2); results 416 from the preliminary assays with AK (Table S5) and summary of the removal of OMPs during 417 AD (Table S6).

\section{AUTHOR INFORMATION}

\section{Corresponding Author}

420 Lorena Gonzalez-Gil

421 Telephone: 0034881816739. E-mail address: lorena.gonzalez@usc.es

\section{$422 \quad$ Notes}

423 The authors declare no competing financial interest.

\section{ACKNOWLEDGEMENTS}

425 This work was funded by Xunta de Galicia through the MicroDAN project (EM 2012/087) 426 and by the Spanish government through the HOLSIA project (CTM2013-46750-R), a Ramón y 427 Cajal contract (RYC-2012-10397) and an FPU Grant (FPU13/01255). The authors belong to 428 CRETUS (AGRUP2015/02) and to the Galician Competitive Research Group (GRC 2013-032). 


\section{REFERENCES}

430

431

432

433

434

435

436

437

438

439

440

441

442

443

444

445

446

447

448

449

450

451

452

453

454

455

456

457

458

459

460

461

462

463

464

465

466

467

(1) Kümmerer, K. Pharmaceuticals in the Environment. Annu. Rev. Environ. Resour. 2010, 35 (1), 57-75.

(2) Santos, L. H. M. L. M.; Araújo, A. N.; Fachini, A.; Pena, A.; Delerue-Matos, C.; Montenegro, M. C. B. S. M. Ecotoxicological aspects related to the presence of pharmaceuticals in the aquatic environment. J. Hazard. Mater. 2010, 175, 45-95.

(3) Stasinakis, A. S. Review on the fate of emerging contaminants during sludge anaerobic digestion. Bioresour. Technol. 2012, 121, 432-440.

(4) Gonzalez-Gil, L.; Papa, M.; Feretti, D.; Ceretti, E.; Mazzoleni, G.; Steimberg, N.; Pedrazzani, R.; Bertanza, G.; Lema, J. M.; Carballa, M. Is anaerobic digestion effective for the removal of organic micropollutants and biological activities from sewage sludge? Water Res. 2016, 102, 211-220.

(5) Chen, F.; Ying, G.-G.; Ma, Y.-B.; Chen, Z.-F.; Lai, H.-J.; Peng, F.-J. Field dissipation and risk assessment of typical personal care products TCC, TCS, AHTN and HHCB in biosolid-amended soils. Sci. Total Environ. 2014, 470-471, 1078-1086.

(6) des Mes, T. Z. D.; Kujawa-Roeleveld, K.; Zeeman, G.; Lettinga, G. Anaerobic biodegradation of estrogens - Hard to digest. Water Sci. Technol. 2008, 57 (8), 11771182 .

(7) Alvarino, T.; Suarez, S.; Lema, J. M.; Omil, F. Understanding the removal mechanisms of PPCPs and the influence of main technological parameters in anaerobic UASB and aerobic CAS reactors. J. Hazard. Mater. 2014, 278, 506-513.

(8) Carballa, M.; Omil, F.; Ternes, T.; Lema, J. M. Fate of pharmaceutical and personal care products (PPCPs) during anaerobic digestion of sewage sludge. Water Res. 2007, 41 (10), 2139-2150.

(9) Narumiya, M.; Nakada, N.; Yamashita, N.; Tanaka, H. Phase distribution and removal of pharmaceuticals and personal care products during anaerobic sludge digestion. J. Hazard. Mater. 2013, 260 (2013), 305-312.

(10) Samaras, V. G.; Stasinakis, A. S.; Thomaidis, N. S.; Mamais, D.; Lekkas, T. D. Fate of selected emerging micropollutants during mesophilic, thermophilic and temperature cophased anaerobic digestion of sewage sludge. Bioresour. Technol. 2014, 162, 365-372.

(11) Malmborg, J.; Magnér, J. Pharmaceutical residues in sewage sludge: Effect of sanitization and anaerobic digestion. J. Environ. Manage. 2015, 153, 1-10.

(12) Yang, S.; Hai, F. I.; Price, W. E.; McDonald, J.; Khan, S. J.; Nghiem, L. D. Occurrence of trace organic contaminants in wastewater sludge and their removals by anaerobic digestion. Bioresour. Technol. 2016, 210, 153-159.

(13) Braun, F.; Hamelin, J.; Bonnafous, A.; Delgenès, N.; Steyer, J.-P.; Patureau, D. Similar $\mathrm{PAH}$ fate in anaerobic digesters inoculated with three microbial communities accumulating either volatile fatty acids or methane. PLoS One 2015, 10 (4), 1-20.

(14) Christy, P. M.; Gopinath, L. R.; Divya, D. A review on anaerobic decomposition and 
enhancement of biogas production through enzymes and microorganisms. Renew. Sustain. Energy Rev. 2014, 34, 167-173.

(15) Guo, J.; Peng, Y.; Ni, B.-J.; Han, X.; Fan, L.; Yuan, Z. Dissecting microbial community structure and methane-producing pathways of a full-scale anaerobic reactor digesting activated sludge from wastewater treatment by metagenomic sequencing. Microb. Cell Fact. 2015, 14 (1), 33.

(16) Fernandez-Fontaina, E.; Pinho, I.; Carballa, M.; Omil, F.; Lema, J. M. Biodegradation kinetic constants and sorption coefficients of micropollutants in membrane bioreactors. Biodegradation 2013, 24 (2), 165-177.

(17) Delgadillo-Mirquez, L.; Lardon, L.; Steyer, J.-P.; Patureau, D. A new dynamic model for bioavailability and cometabolism of micropollutants during anaerobic digestion. Water Res. 2011, 45 (15), 4511-4521.

(18) Pomiès, M.; Choubert, J.-M.; Wisniewski, C.; Coquery, M. Modelling of micropollutant removal in biological wastewater treatments: a review. Sci. Total Environ. 2013, 443, $733-748$.

(19) Plósz, B. G.; Leknes, H.; Thomas, K. V. Impacts of competitive inhibition, parent compound formation and partitioning behavior on the removal of antibiotics in municipal wastewater treatment. Environ. Sci. Technol. 2010, 44 (2), 734-742.

(20) Criddle, C. S. The kinetics of cometabolism. Biotechnol. Bioeng. 1993, 41 (11), 10481056.

(21) Fischer, K.; Majewsky, M. Cometabolic degradation of organic wastewater micropollutants by activated sludge and sludge-inherent microorganisms. Appl. Microbiol. Biotechnol. 2014, 98 (15), 6583-6597.

(22) Fernandez-Fontaina, E.; Gomes, I. B.; Aga, D. S.; Omil, F.; Lema, J. M.; Carballa, M. Biotransformation of pharmaceuticals under nitrification, nitratation and heterotrophic conditions. Sci. Total Environ. 2015, 541, 1439-1447.

(23) Kassotaki, E.; Buttiglieri, G.; Ferrando-Climent, L.; Rodriguez-Roda, I.; Pijuan, M. Enhanced sulfamethoxazole degradation through ammonia oxidizing bacteria cometabolism and fate of transformation products. Water Res. 2016, 94, 111-119.

(24) Krah, D.; Ghattas, A.-K.; Wick, A.; Bröder, K.; Ternes, T. a. Micropollutant degradation via extracted native enzymes from activated sludge. Water Res. 2016, 95, 348-360.

(25) Trably, E.; Patureau, D.; Delgenes, J. P. Enhancement of polycyclic aromatic hydrocarbons removal during anaerobic treatment of urban sludge. Water Sci. Technol. 2003, 48 (4), 53-60.

(26) Conrad, R. Contribution of hydrogen to methane production and control of hydrogen concentrations in methanogenic soils and sediments. FEMS Microbiol. Ecol. 1999, 28 (3), $193-202$.

(27) Gorrell, A.; Ferry, J. G. Investigation of the Methanosarcina thermophila Acetate Kinase Mechanism by Fluorescence Quenching. Biochemistry 2007, 46, 14170-14176. 
(28) Ferry, J. G. Acetate Kinase and Phosphotransacetylase. In Methods in Methane Metabolism, Part A; Elsevier Inc., 2011; Vol. 494, pp 219-231.

(29) Iyer, P.; Ferry, J. G. Acetate Kinase from Methanosarcina thermophila, a Key Enzyme for Methanogenesis. In Methods in Biotechnology-Microbial Enzymes and Biotransformations; José Luis, B., Ed.; Humana Press Inc: Totowa, New Jersey, 2005; Vol. 17, pp 239-246.

(30) Aceti, D. J.; Ferry, G. Purification and characterization of Acetate Kinase from Acetategrown Methanosarcina thermophila. J. Biol. Chem. 1988, 263 (30), 15444-15448.

(31) Langford, K. H.; Reid, M.; Thomas, K. V. Multi-residue screening of prioritised human pharmaceuticals, illicit drugs and bactericides in sediments and sludge. J. Environ. Monit. 2011, 13 (8), 2284-2291.

(32) Radjenović, J.; Petrović, M.; Barceló, D. Fate and distribution of pharmaceuticals in wastewater and sewage sludge of the conventional activated sludge (CAS) and advanced membrane bioreactor (MBR) treatment. Water Res. 2009, 43 (3), 831-841.

(33) Bolz, U.; Hagenmaier, H.; Körner, W. Phenolic xenoestrogens in surface water, sediments, and sewage sludge from Baden-Württemberg, south-west Germany. Environ. Pollut. 2001, 115 (2), 291-301.

(34) Demirel, B.; Scherer, P. The roles of acetotrophic and hydrogenotrophic methanogens during anaerobic conversion of biomass to methane: A review. Rev. Environ. Sci. Biotechnol. 2008, 7 (2), 173-190.

(35) Regueiro, L.; Lema, J. M.; Carballa, M. Key microbial communities steering the functioning of anaerobic digesters during hydraulic and organic overloading shocks. Bioresour. Technol. 2015, 197, 208-216.

(36) De Vrieze, J.; Hennebel, T.; Boon, N.; Verstraete, W. Methanosarcina: the rediscovered methanogen for heavy duty biomethanation. Bioresour. Technol. 2012, 112, 1-9.

(37) Rose, I. A.; Grunberg-Manago, M.; Korey, S. R.; Ochoa, S. Enzymatic phosphorylation of acetate. J. Biol ogical Chem. 1954.

(38) Lipmann, F.; Tuttle, L. . C. A specific micromethod for the determination of acyl phopsphates. J. Biol. Chem. 1945.

(39) Bock, A. K.; Glasemacher, J.; Schmidt, R.; Schönheit, P. Purification and characterization of two extremely thermostable enzymes, phosphate acetyltransferase and acetate kinase, from the hyperthermophilic eubacterium Thermotoga maritima. J. Bacteriol. 1999, 181 (6), 1861-1867.

(40) Mu, H.; Chen, Y.; Xiao, N. Effects of metal oxide nanoparticles (TiO2, A12O3, SiO2 and $\mathrm{ZnO}$ ) on waste activated sludge anaerobic digestion. Bioresour. Technol. 2011, 102 (22), 10305-10311.

(41) Gorrell, A.; Lawrence, S. H.; Ferry, J. G.; Bacteriol, J. Structural and Kinetic Analyses of Arginine Residues in the Active Site of the Acetate Kinase from Methanosarcina thermophila. J. Biol. Chem. 2005, 280 (11), 10731-10742. 
546
(42) Ingram-Smith, C.; Gorrell, A.; Lawrence, S. H.; Iyer, P.; Smith, K.; Ferry, J. G. Characterization of the Acetate Binding Pocket in the Methanosarcina thermophila Acetate Kinase. J. Bacteriol. 2005, 187 (7), 2386-2394.

(43) Bisswanger, H. Enzyme assays. Perspect. Sci. 2014, 1 (1-6), 41-55.

(44) APHA. Standard Methods for the Examination of Water and Wastewater, 21st ed.; American Public Health Association/American Water Works Association/Water Environment Federation: Washington DC, USA, 2005.

(45) Clara, M.; Gans, O.; Windhofer, G.; Krenn, U.; Hartl, W.; Braun, K.; Scharf, S.; Scheffknecht, C. Occurrence of polycyclic musks in wastewater and receiving water bodies and fate during wastewater treatment. Chemosphere 2011, 82 (8), 1116-1123.

(46) Paterakis, N.; Chiu, T. Y.; Koh, Y. K. K.; Lester, J. N.; McAdam, E. J.; Scrimshaw, M. D.; Soares, A.; Cartmell, E. The effectiveness of anaerobic digestion in removing estrogens and nonylphenol ethoxylates. J. Hazard. Mater. 2012, 199-200, 88-95.

(47) Bergersen, O.; Østnes, K.; Vasskog, T. Bioresource Technology Anaerobic treatment of sewage sludge containing selective serotonin reuptake inhibitors. Bioresour. Technol. 2012, 117, 325-332.

(48) Wang, Q.; Wei, C.; Pérez, L. M.; Rogers, W. J.; Hall, M. B.; Mannan, M. S. Thermal decomposition pathways of hydroxylamine: theoretical investigation on the initial steps. $J$. Phys. Chem. A 2010, 114 (34), 9262-9269.

(49) Ferry, J. G. The chemical biology of methanogenesis. Planet. Space Sci. 2010, 58 (14-15), $1775-1783$.

(50) Stams, A. J. M. Metabolic interactions between anaerobic bacteria in methanogenic environments. Antonie Van Leeuwenhoek 1994, 66, 271-294.

(51) Allen, S. H.; Kellermeyer, R. W.; Stjernholm, R. L.; Wood, H. G. Purification and Properties of Enzymes Involved in the Propionic Acid Fermentation. J. Bacteriol. 1964, 87, 171-187. 